\title{
Antidepressant-like activity of turmerone in behavioral despair tests in mice
}

\author{
Jung-Chun Liao ${ }^{1 \dagger}$, Jen-Chieh Tsai ${ }^{2}$, Chia-Yu Liu ${ }^{3,4+}$, Hui-Chi Huang ${ }^{3}$, Lung-Yuan Wu ${ }^{5^{*}}$ and Wen-Huang Peng ${ }^{3^{*}}$
}

\begin{abstract}
Background: The present study was undertaken to evaluate the anti-depressive activity of turmerone after one-week administration by using a mouse forced swimming test (FST) and tail suspension test (TST).
\end{abstract}

Methods: Animals were divided into four groups ( $n=10 /$ group): control ( $0.9 \%$ saline), the three doses of turmerone $(1.25,2.5,5.0 \mathrm{mg} / \mathrm{kg})$ for one-week treatment. To assess the effect of turmerone on locomotor activity, mice were evaluated in the open-field paradigm. Forced swimming test (FST) and Tail suspension test (TST) were used to take as a measure of antidepressant activity. The probable mechanisms of action of the anti-depressive effect of turmerone was also investigated by measuring the activity of monoamine oxidase-A and corticosterone levels in the blood and the levels of monoamines in the cortex, striatum, hippocampus and hypothalamus of the mice.

Results: Turmerone $(2.5,5.0 \mathrm{mg} / \mathrm{kg}$, p.o.) significantly reduced the immobility time of mice in both the FST and TST, but it did not significantly affect the ambulatory and total movements of mice. However, hyperactivity might explain the results. In addition, turmerone decreased the corticosterone level in the blood while it increased the levels of 5-HT in cortex, striatum, hippocampus, and hypothalamus, the level of NE in striatum and hippocampus, the levels of MHPG and DOPAC in hypothalamus, the level of 5-HIAA in striatum, and the level of DA in striatum, hippocampus, and hypothalamus. Turmerone $(2.5,5.0 \mathrm{mg} / \mathrm{kg})$ decreased the activity of MAO-A in the frontal cortex and hippocampus of mouse brain.

Conclusions: After one-week administration, turmerone produced antidepressant-like effects. The mechanisms of action of anti-depressive effect of turmerone seemed to involve an increase of the monoamines level decreasing the MAO-A activity and the stress of mice.

Keywords: Tumerone, Forced swimming test, Tail suspension test, Antidepressant, Monoamines

\section{Background}

Depression, a highly debilitating and widely distributed illness in the general population, is ranked by the World Health Organization as among the most burdensome diseases of society [1]. Affective disorder presents with depressed mood, loss of interest or pleasure, feelings of guilt or low self-worth, disturbed sleep or appetite, low energy, and poor concentration [2]. An important theory to explain the cause of depression is the monoamine hypothesis which suggests that there is impairment of monoaminergic functions and the decrease of serotonin,

\footnotetext{
*Correspondence: df6689@yahoo.com.tw; whpeng@mail.cmu.edu.tw ${ }^{\dagger}$ Equal contributors

${ }^{5}$ School of Chinese Medicine for Post Baccalaureate, I-Shou university, No.1, Sec. 1, Syuecheng Rd., Dashu District, Kaohsiung City 84001, Taiwan

${ }^{3}$ Department of Chinese Pharmaceutical Sciences and Chinese Medicine Resources, College of Pharmacy, China Medical University, No. 91, Hsueh-Shih Road, Taichung 404, Taiwan

Full list of author information is available at the end of the article
}

norepinephrine and dopamine levels [3,4]. At present, there are several types of antidepressants used in clinical practice, including tricyclic antidepressants (TCAs), selective serotonin reuptake inhibitors (SSRIs), selective reversible inhibitors of monoamine oxidase A (RIMAs), and specific serotonin-norepinephrine reuptake inhibitors (SNRIs) [5], however, these drugs can produce many side-effects, therefore, considerable efforts are being invested in the discovery of better drugs for the treatment of depression [6].

Herbal medicines such as St. John's wort have been used as alternative therapies for depression [7]. Curcuma longa (Family: Zingiberaceae), also called $Y u$-jin in Chinese, has long been used in food and medicine. Curcuma drugs (e.g., C. longa) which were indicated for liver $q i$ stagnation in Traditional Chinese Medicine, were selected for testing as a possible depression treatment [8]. Turmerone, an active constituent of C. longa, has been

\section{Biomed Central}


shown to possess powerful antioxidant, anti-inflammatory, anti-tumor, and anti-proliferative activities [9-13]. Inflammation is typically characterized by redness, swelling, pain, and heat. Depression is frequent in chronic pain patients and it has been suggested that pain and depression share common neurochemical mechanisms [14]. In several studies some antidepressant drugs afforded an integral alleviation of pain [15]. Curcumin has been shown to possess antidepressantlike effects in animal models commonly employed for the prediction of antidepressant activity [16-18]. It is worthy to investigate whether turmerone, an analog of curcumin [19], would possess antidepressant activity. In the present study, we aimed to test the anti-depressant effect of turmerone in mice using FST and TST. Behavioral despair tests have good predictive value for antidepressant potency in humans [20]. Moreover, we determined whether the alteration of monoamine levels and monoamine oxidase A (MAO-A) activities might predict the antidepressant properties of turmerone. We evaluated the effect of turmerone on the neuroendocrine system by measuring alterations in serum corticosterone which is involved in the mouse FST model of depression.

\section{Methods}

\section{Animals}

Male ICR mice (weighing around $22 \mathrm{~g}$ ), purchased from BioLASCO Taiwan Co., Ltd. (Yi-Lan, Taiwan) were used in the present study. They were maintained at $22 \pm 1^{\circ} \mathrm{C}$ with free access to water and food, under a 12:12 $\mathrm{h}$ light/dark cycle (lights on at 08:00 h). All manipulations were carried out between 9:00 and 15:00 h, with each animal used only once. All procedures in this study were performed in accordance with the NIH Guide for the Care and Use of Laboratory Animals. The experimental protocol was approved by the Committee on Animal Research, China Medical University. The minimum number of animals and duration of observations required to obtain consistent data were used.

\section{Chemicals and reagents}

Turmerone (CAS no. 82508-15-4) was purchased from Allichem LLC (Baltimore, MD, USA). All drugs were administered by oral route. The p.o. administrations were given in a volume of $10 \mathrm{ml} / \mathrm{kg}$ body weight. Tests were performed $1 \mathrm{hr}$ after administration of turmerone. The monoamine standards: norepinephrine (NE), dopamine (DA), 5-hydroxytryptamine (5-HT), 4-hydroxy-3-methoxyphenylglycol (MHPG), 3, 4-dihydroxyphenylacetic acid (DOPAC) and 5-hydroxyindole-3-acetic acid (5-HIAA) were purchased from Sigma-Aldrich (Steinheim, Germany). Ethylenediamine tetraacetic acid (EDTA) was purchased from Merck (Darmstadt, Germany). Sodium dihydrogen phosphate monohydrate $\left(\mathrm{NaH}_{2} \mathrm{PO}_{4} \cdot \mathrm{H}_{2} \mathrm{O}\right)$ was purchased from J.T. Baker (Phillipsburg, PA, USA). Sodium 1-octane sulfonate was purchased from TCI (Tokyo, Japan). Methanol and ethanol were purchased from Uni-Onward Company (Taipei, Taiwan). All other chemicals were of reagent grade or better.

\section{Behavior despair study}

For FST and TST, animals were divided into five groups ( $\mathrm{n}=10$ /group): control (0.9\% saline), FLU $10 \mathrm{mg} / \mathrm{kg}$, and the three doses of turmerone $(1.25,2.5,5.0 \mathrm{mg} / \mathrm{kg})$ for one-week treatment.

\section{Forced swimming test (FST)}

The method was carried out on mice according to the method of Porsolt et al. [21]. Mice were placed in an open cylindrical container (diameter $10 \mathrm{~cm}$, height $25 \mathrm{~cm}$ ), containing $15 \mathrm{~cm}$ of water at $25 \pm 1^{\circ} \mathrm{C}$. The duration of observed immobility was recorded during the last $4 \mathrm{~min}$ of the 6-min testing period [22]. Immobile time was defined as the absence of active/escape directed movements (mouse floating in the water without struggling) and was scored in a blind manner by an observer [23]. Decrease in the duration of immobility during the FST was taken as a measure of antidepressant activity.

\section{Tail suspension test (TST)}

The total duration of immobility induced by tail suspension was measured according to the method of Steru et al. [24]. Mice both acoustically and visually isolated were suspended $50 \mathrm{~cm}$ above the floor by adhesive tape placed approximately $1 \mathrm{~cm}$ from the tip of the tail. The time during which mice remained immobile was quantified during a test period of $6 \mathrm{~min}$. Mice were considered immobile only when they hung passively and completely motionless.

\section{Open-field test}

For open-field test, animals were divided into four groups ( $\mathrm{n}=10$ /group): control ( $0.9 \%$ saline), the three doses of turmerone $(1.25,2.5,5.0 \mathrm{mg} / \mathrm{kg})$ for one-week treatment.

To assess the effect of turmerone on locomotor activity, mice were evaluated in the open-field paradigm (TRU SCAN Activity Monitoring Systems, Coulbourn Instruments) previously described [25]. Animals were individually placed in a box $(40 \times 60 \times 50 \mathrm{~cm})$. The mice were not habituated to the box before the test. The mice were placed in the center and their behavior was noted immediately and continued for $4 \mathrm{~min}$. The parameters such as total movements, total distance, total ambulatory move time were recorded by video camera and registered in the computer. During the interval of the test the apparatus was cleaned. 
Determination of monoamines and their metabolites levels in the mice frontal cortex, striatum, hippocampus, and hypothalamus.

Animals were divided into five groups ( $\mathrm{n}=10$ /group): control ( $0.9 \%$ saline), control vs. FST, FLU $(10 \mathrm{mg} / \mathrm{kg})$, and the two doses of turmerone $(2.5,5.0 \mathrm{mg} / \mathrm{kg})$ for one-week treatment. The mice were killed after the FST which was performed $1 \mathrm{hr}$ after the last administration.

Monoamines were measured according to the method of Renard et al. [26]. Briefly, mice were killed by cervical dislocation without anesthesia just after the FST. The brain was removed after a rapid dissection of frontal cortex, striatum (included the nucleus accumbens), hippocampus and hypothalamus were isolated. The four brain tissues were weighed, and placed separately in $5 \mathrm{ml}$ of ice-cold homogenizing solution $(8.8 \mathrm{mg}$ of ascorbic acid and $122 \mathrm{mg}$ of EDTA in $1000 \mathrm{ml}$ of perchloric acid $0.1 \mathrm{M})$. After homogenization, the solution was centrifuged at $10,000 \times \mathrm{g}$ for $10 \mathrm{~min}$ at $4^{\circ} \mathrm{C}$. Twenty microliters of the resultant supernatant was injected in the high performance liquid chromatography (HPLC) system. The levels of monoamines
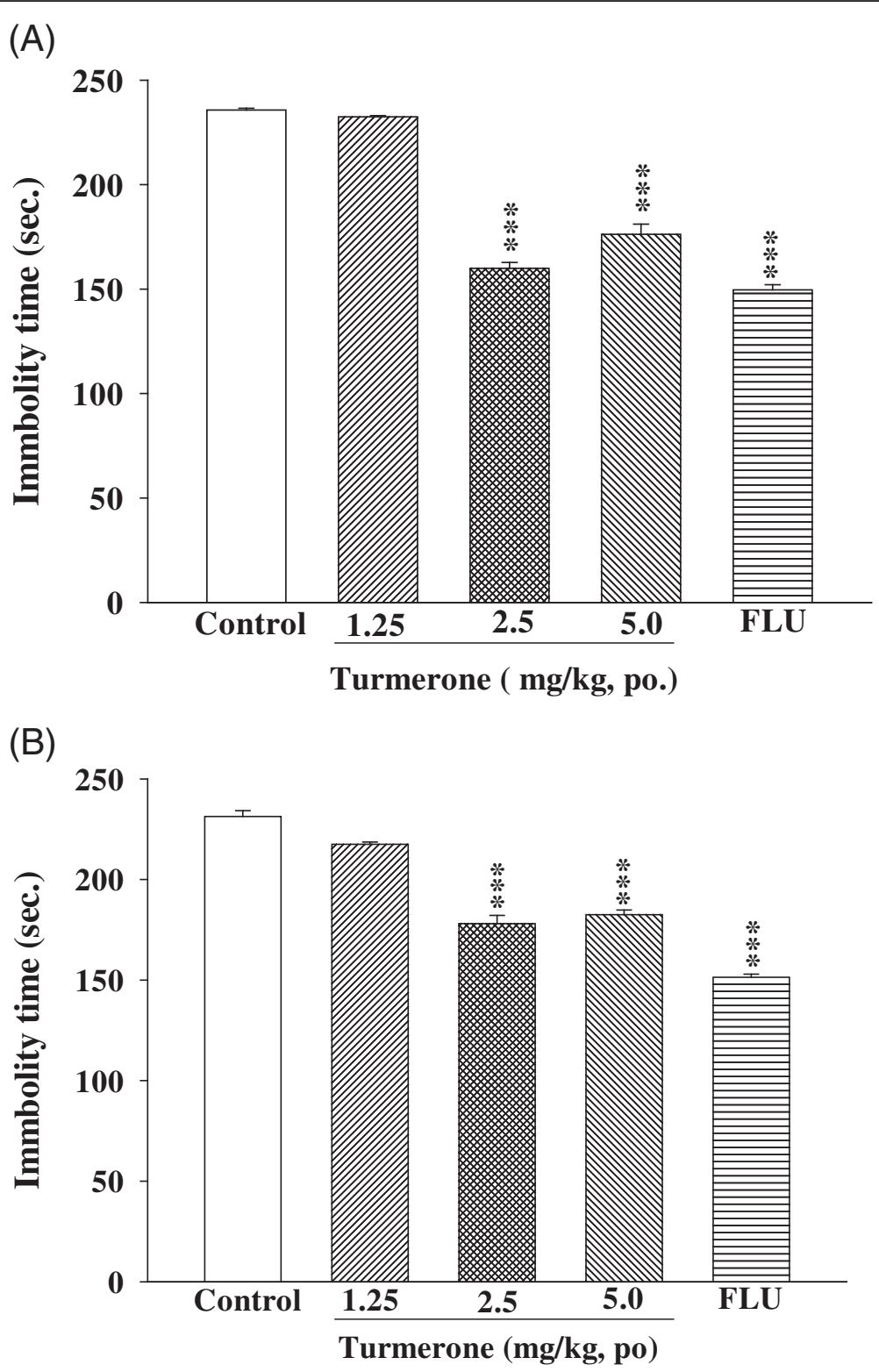

Figure 1 The effect of turmerone (1.25-5.0 mg/kg, p.o.), or fluoxetine (FLU, $10 \mathrm{mg} / \mathrm{kg}, \mathrm{p.o}$.) on the immobility time in the forced swimming (A) and tail suspension (B) tests after one week of administration. The values are mean \pm SEM for each group $(n=10)$. ${ }^{* * *} \mathrm{p}<0.001$ as compared with control group (One-way ANOVA followed by Scheffe's multiple range test). 


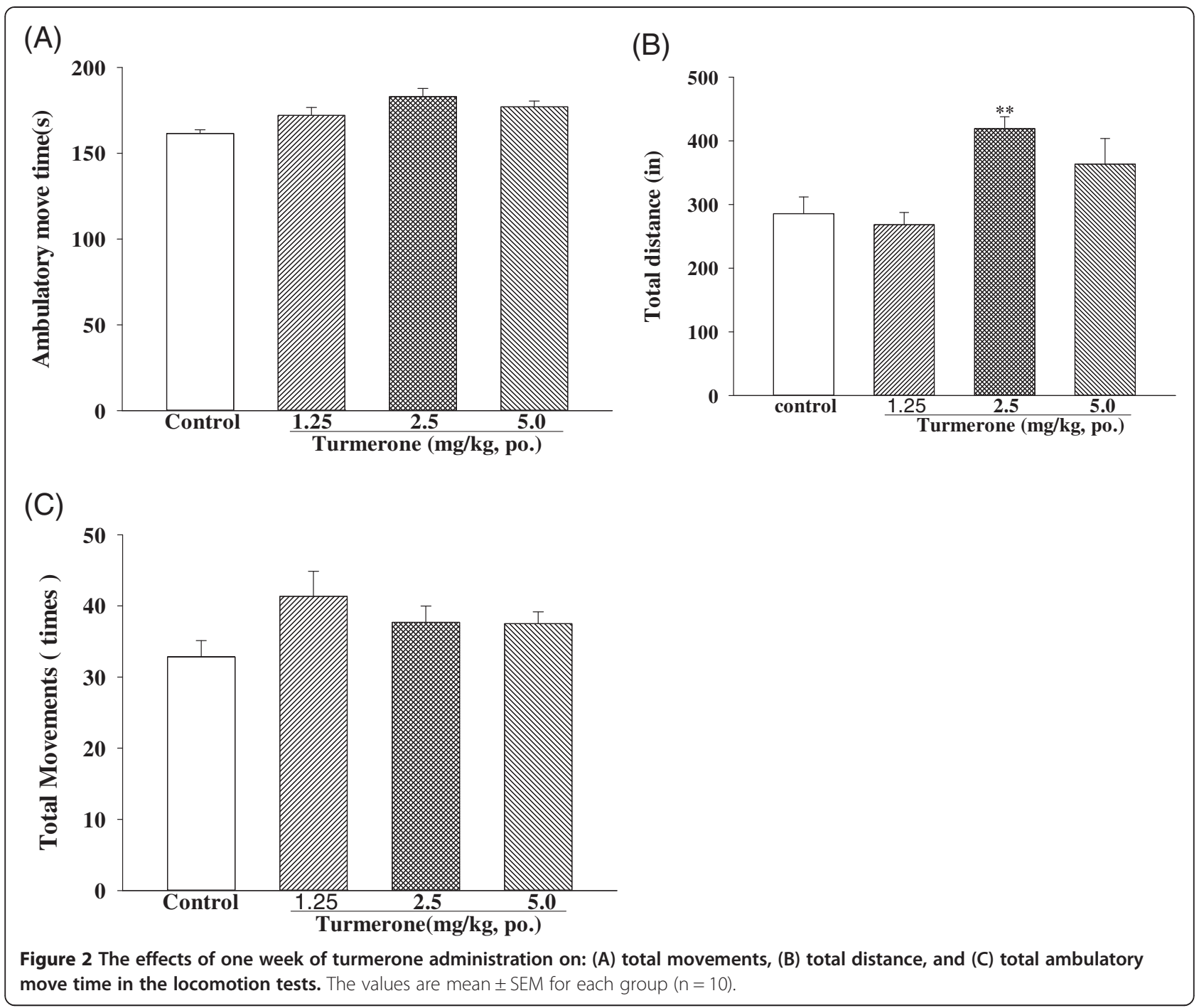

(NE, DA and 5-HT) and their metabolites (MHPG, DOPAC, 5-HIAA) were measured by HPLC (Waters 610) with electrochemical detection in the four brain tissues. The mobile phase $[4.2 \mathrm{~g} / \mathrm{l}$ citric acid monohydrate, $6.8 \mathrm{~g} / \mathrm{l}$ sodium acetate trihydrate, $0.8 \mathrm{~g} / \mathrm{l}$ octanesulfonic acid sodium salt, $0.05 \mathrm{~g} / \mathrm{l}$ tetrasodium ethylenediamine tetraacetate, $0.02 \%(\mathrm{v} / \mathrm{v})$ dibutyl amine, and $7 \%(\mathrm{v} / \mathrm{v})$ methyl alcohol] was delivered at $1.0 \mathrm{ml} / \mathrm{min}$. The reverse-phase column used was a Merk Lichrospher 100 RP-18 endcapped column with a length of $12.5 \mathrm{~cm}$

Table 1 Effect of turmerone on the concentrations ( $\mathrm{ng} / \mathrm{g}$ tissue) of monoamines and their metabolites in the cortex of mice brain

\begin{tabular}{llllllll}
\hline \multicolumn{1}{c}{ Group } & \multicolumn{1}{c}{ NE } & \multicolumn{1}{c}{ MHPG } & \multicolumn{1}{c}{ DA } & DOPAC & 5-HT & 5-HIAA & 5-HIAA/5-HT \\
\hline Normal & $402.4 \pm 19.8$ & $243.1 \pm 6.2$ & $83.5 \pm 5.6$ & $72.2 \pm 2.7$ & $432.1 \pm 22.3$ & $127.2 \pm 7.7$ & $0.30 \pm 0.03$ \\
Control + FST & $200.5 \pm 23.5^{\# \# \#}$ & $228.9 \pm 15.6$ & $48.1 \pm 2.0^{\# \#}$ & $44.6 \pm 1.5$ & $326.9 \pm 15.5^{\#}$ & $255.2 \pm 41.8^{\# \#}$ & $0.75 \pm 0.14^{\# \#}$ \\
Fluoxetine 10 mg/kg + FST & $283.4 \pm 3.3$ & $180.4 \pm 7.6$ & $58.7 \pm 1.7$ & $47.4 \pm 1.8$ & $600.2 \pm 6.1^{* * *}$ & $214.3 \pm 3.3$ & $0.36 \pm 0.01^{* *}$ \\
Turmerone 2.5 mg/kg + FST & $254.9 \pm 9.1$ & $172.4 \pm 5.2$ & $69.7 \pm 6.3$ & $46.9 \pm 1.4$ & $734.8 \pm 18.6^{* * *}$ & $237.0 \pm 22.0$ & $0.33 \pm 0.03^{* *}$ \\
Turmerone 5.0 mg/kg + FST & $384.2 \pm 31.3^{* * *}$ & $179.3 \pm 5.5^{*}$ & $48.6 \pm 8.6$ & $42.5 \pm 2.5$ & $629.9 \pm 25.5^{* * *}$ & $250.2 \pm 14.0$ & $0.42 \pm 0.02$ \\
\hline
\end{tabular}

Values were the means \pm SEM $(\mathrm{n}=10) .{ }^{\#} p<0.05,{ }^{\# \#} p<0.01,{ }^{\# \# \#} p<0.001$ as compared with the normal group. ${ }^{* *} p<0.01,{ }^{* * *} p<0.001$ as compared with the control + FST group. (One-way ANOVA followed by Scheffe's test). NE: norepinephrine, MHPG: 3 methoxy-4-hydroxyphenylglycol, DA: dopamine, DOPAC: 3,4-dihydroxyphenylacetic acid, 5-HT: serotonin, 5-HIAA: 5-hydroxyindoleacetic acid. 
Table 2 Effect of turmerone on the concentrations ( $\mathrm{ng} / \mathrm{g}$ tissue) of monoamines and their metabolites in the striatum of mice brain

\begin{tabular}{llllllll}
\hline Group & \multicolumn{1}{c}{ NE } & MHPG & \multicolumn{1}{c}{ DA } & DOPAC & 5-HT & 5-HIAA & 5-HIAA/5-HT \\
\hline Normal & $356.0 \pm 9.6$ & $238.0 \pm 12.4$ & $526.0 \pm 9.2$ & $157.7 \pm 14.8$ & $353.3 \pm 18.7$ & $214.1 \pm 8.5$ & $0.62 \pm 0.05$ \\
Control + FST & $262.3 \pm 19.4$ & $261.3 \pm 9.6$ & $342.9 \pm 8.2^{\# \# \#}$ & $150.1 \pm 7.2$ & $253.9 \pm 9.8^{\# \#}$ & $283.0 \pm 2.9$ & $1.07 \pm 0.08^{\# \# \#}$ \\
Fluoxetine 10 mg/kg + FST & $310.4 \pm 4.7$ & $236.2 \pm 4.8$ & $413.8 \pm 5.0$ & $144.6 \pm 2.2$ & $599.6 \pm 8.8^{* * *}$ & $204.7 \pm 3.4$ & $0.34 \pm 0.01^{* * *}$ \\
Turmerone 2.5 mg/kg + FST & $379.1 \pm 43.2^{*}$ & $256.4 \pm 3.3$ & $933.5 \pm 23.1^{* * *}$ & $129.7 \pm 5.6$ & $852.8 \pm 15.3^{* * *}$ & $206.4 \pm 5.6^{*}$ & $0.26 \pm 0.01^{* * *}$ \\
Turmerone 5.0 mg/kg + FST & $327.8 \pm 12.7$ & $253.3 \pm 6.8$ & $776.9 \pm 23.8^{* * *}$ & $137.5 \pm 5.3$ & $731.8 \pm 17.6^{* * *}$ & $204.2 \pm 20.9^{*}$ & $0.28 \pm 0.03^{* * *}$ \\
\hline
\end{tabular}

Values were the means \pm SEM $(n=10) .{ }^{*} p<0.05$, ${ }^{\# \# \# ~} p<0.001$ as compared with the normal group. ${ }^{*} p<0.05,{ }^{* *} p<0.01,{ }^{* * *} p<0.001$ as compared with the control + FST group. (One-way ANOVA following by Scheffe's test). NE: norepinephrine, MHPG: 3 methoxy-4-hydroxyphenylglycol, DA: dopamine, DOPAC: 3,4-dihydroxyphenylacetic acid, 5-HT: serotonin, 5-HIAA: 5-hydroxyindoleacetic acid.

and an internal diameter of $4.0 \mathrm{~mm}$ (E. Merk 50734). The compounds were measured at $+0.75 \mathrm{~V}$ using a Bioanalytical Systems LC-4C electrochemical detector.

\section{Measurements of monoamine oxidase (MAO) activity}

Animals were divided into four groups ( $\mathrm{n}=10 /$ group): control ( $0.9 \%$ saline), and two doses of turmerone (2.5, $5.0 \mathrm{mg} / \mathrm{kg}$, for one week' administration). The mice were killed after the FST which was performed $1 \mathrm{hr}$ after the last administration.

Mouse brain fraction was prepared following the procedure described previously [27]. Briefly, the fraction suspended in 10 volume of cold sodium phosphate buffer (10 mM, pH 7.4, containing $320 \mathrm{mM}$ sucrose), was mingled at $48^{\circ} \mathrm{C}$ for $20 \mathrm{~min}$. The mixture was centrifuged at $15,000 \mathrm{~g}$ for $30 \mathrm{~min}$ at $8^{\circ} \mathrm{C}$ and the pellets were re-suspended in the same buffer. The protein concentration was adjusted to $1 \mathrm{mg} / \mathrm{ml}$. Protein concentration was measured by the Lowry method [28] using bovine serum albumin as the standard. The MAO activity was assessed spectrophotometrically as described previously [8]. The assay mixtures contained $4 \mathrm{mM} 5$ - $\mathrm{HT}$ as specific substrates for MAO-A, $250 \mathrm{ml}$ solution of the fraction, and $100 \mathrm{mM}$ sodium phosphate buffer ( $\mathrm{pH} 7.4)$ up to a final volume of $1 \mathrm{ml}$. The reaction was allowed to proceed at $37^{\circ} \mathrm{C}$ for $20 \mathrm{~min}$, and stopped by adding $1 \mathrm{M} \mathrm{HCl}$ $(200 \mathrm{ml})$, the reaction product was extracted with $5 \mathrm{ml}$ of butyl acetate (for MAO-A assay). The organic phase was measured at wavelength of $280 \mathrm{~nm}$ for MAO-A assay with spectrophotometer, respectively. Blank samples were prepared by adding $1 \mathrm{M} \mathrm{HCl}(200 \mathrm{ml})$ prior to reaction, and worked up subsequently in the same manner.

\section{Blood sampling and corticosterone measurement}

Animals were divided into four groups ( $\mathrm{n}=6$ /group): control $(0.9 \%$ saline $)$, control vs. FST, the two doses of turmerone $(2.5,5.0 \mathrm{mg} / \mathrm{kg})$ for one-week treatment.

The animals were sacrificed $1 \mathrm{hr}$ after the last administration for blood sampling between 04:00 and 06:00 p.m. The abdominal aorta was punctured under intramuscular (i.m.) ketamine hydrochloride $(10 \%, 0.35 \mathrm{ml}$ ) and medetomidine hydrochloride $(0.001 \%, 0.05 \mathrm{ml})$ anesthesia. The collected blood was heparinized and centrifuged by $400 \mathrm{~g}$ for $10 \mathrm{~min}$. Corticosterone was measured with an automatic chemiluminescence Immunoassay system (Advia Centaur, Bayer, Bad Nauheim, Germany) [29].

\section{Statistical analysis}

All results are expressed as mean \pm SEM. Data were analyzed by one-way ANOVA followed by Scheffe's multiple range test. The criterion for statistical significance was $\mathrm{p}<0.05$. All statistical analyses were carried out by using SPSS for Windows (SPSS Inc.).

\section{Results}

Turmerone caused a reduction in the immobility time in FST $(\mathrm{F}(4,45)=346.4)$ and TST $(\mathrm{F}(4,45)=249.8)($ dose range: $1.25-5.0 \mathrm{mg} / \mathrm{kg}$, p.o.; Figure 1$)$.

Turmerone did not affect total movement and ambulatory movement at the same doses that significantly

Table 3 Effect of turmerone on the concentrations ( $\mathrm{ng} / \mathrm{g}$ tissue) of monoamines and their metabolites in the hippocampus of mice brain

\begin{tabular}{|c|c|c|c|c|c|c|c|}
\hline Group & NE & MHPG & DA & DOPAC & 5-HT & 5-HIAA & 5-HIAA/5-HT \\
\hline Normal & $290.6 \pm 23.8$ & $244.4 \pm 14.9$ & $50.1 \pm 2.0$ & $31.9 \pm 0.7$ & $406.5 \pm 14.7$ & $198.9 \pm 3.5$ & $0.51 \pm 0.03$ \\
\hline Control + FST & $220.3 \pm 10.3$ & $257.0 \pm 11.8$ & $41.9 \pm 1.4$ & $38.0 \pm 1.1$ & $216.6 \pm 5.5^{\# \# \#}$ & $216.1 \pm 9.6$ & $1.01 \pm 0.07^{\# \# \#}$ \\
\hline Fluoxetine $10 \mathrm{mg} / \mathrm{kg}+\mathrm{FST}$ & $299.7 \pm 5.2$ & $243.0 \pm 5.3$ & $49.6 \pm 1.4$ & $31.0 \pm 1.8$ & $400.0 \pm 5.2^{* * *}$ & $194.0 \pm 6.2$ & $0.49 \pm 0.02^{* * *}$ \\
\hline Turmerone 2.5 mg/kg + FST & $398.0 \pm 31.8^{* * *}$ & $228.0 \pm 15.2$ & $82.7 \pm 2.0^{* * *}$ & $31.5 \pm 0.9$ & $489.1 \pm 12.1^{* * *}$ & $176.8 \pm 13.7$ & $0.37 \pm 0.03^{* * *}$ \\
\hline Turmerone 5.0 mg/kg + FST & $386.1 \pm 11.9^{* * *}$ & $227.0 \pm 18.8$ & $60.4 \pm 1.8^{* * *}$ & $31.5 \pm 0.8$ & $573.1 \pm 20.5^{* * *}$ & $185.5 \pm 24.9$ & $0.32 \pm 0.05^{* * *}$ \\
\hline
\end{tabular}

Values were the means \pm SEM $(n=10)$. \#\#\# $p<0.001$ as compared with the normal group. ${ }^{* * *} p<0.001$ as compared with the control + FST group. (One-way ANOVA followed by Scheffe's test). NE: norepinephrine, MHPG: 3 methoxy-4-hydroxyphenylglycol, DA: dopamine, DOPAC: 3,4-dihydroxyphenylacetic acid, 5-HT: serotonin, 5-HIAA: 5-hydroxyindoleacetic acid. 
Table 4 Effect of turmerone on the concentrations ( $\mathrm{ng} / \mathrm{g}$ tissue) of monoamines and their metabolites in the hypothalamus of mice brain

\begin{tabular}{lccccccc}
\hline Group & \multicolumn{1}{c}{ NE } & \multicolumn{1}{c}{ MHPG } & \multicolumn{1}{c}{ DA } & DOPAC & 5-HT & 5-HIAA & 5-HIAA/5-HT \\
\hline Normal & $267.4 \pm 7.7$ & $201.6 \pm 7.8$ & $437.3 \pm 13.0$ & $111.0 \pm 7.9$ & $345.6 \pm 21.8$ & $145.7 \pm 13.5$ & $0.44 \pm 0.06$ \\
Control + FST & $207.5 \pm 3.2$ & $217.9 \pm 8.8$ & $343.6 \pm 12.9^{\# \# \#}$ & $183.4 \pm 7.9$ & $216.7 \pm 10.4^{\# \# \#}$ & $238.0 \pm 13.8^{\# \#}$ & $0.11 \pm 0.05^{\# \# \#}$ \\
Fluoxetine 10 mg/kg + FST & $224.7 \pm 2.6$ & $202.5 \pm 3.1$ & $363.1 \pm 3.3$ & $143.1 \pm 3.2$ & $422.7 \pm 3.3^{* * *}$ & $204.6 \pm 3.4$ & $0.48 \pm 0.10^{* * *}$ \\
Turmerone 2.5 mg/kg + FST & $246.1 \pm 11.0$ & $166.9 \pm 16.4^{*}$ & $555.3 \pm 11.4^{* * *}$ & $124.2 \pm 7.7^{*}$ & $483.0 \pm 18.5^{* * *}$ & $219.7 \pm 14.0$ & $0.45 \pm 0.02^{* * *}$ \\
Turmerone 5.0 mg/kg + FST & $230.6 \pm 13.0$ & $196.2 \pm 3.0$ & $436.6 \pm 11.6^{* * *}$ & $157.3 \pm 16.1$ & $539.4 \pm 10.5^{* * *}$ & $225.4 \pm 13.8$ & $0.42 \pm 0.02^{* * *}$ \\
\hline
\end{tabular}

Values were the means \pm SEM $(\mathrm{n}=10) .{ }^{\# \#} p<0.01,{ }^{\# \# \#} p<0.001$ as compared with the normal group. ${ }^{*} p<0.05,{ }^{* * *} p<0.001$ as compared with the control + FST group. (One-way ANOVA followed by Scheffe's test). NE: norepinephrine, MHPG: 3 methoxy-4-hydroxyphenylglycol, DA: dopamine, DOPAC: 3,4-dihydroxyphenylacetic acid, 5-HT: serotonin, 5-HIAA: 5-hydroxyindoleacetic acid.

reduced immobility response in the FST and TST (Figure 2). The total distance $[\mathrm{F}(3,36)=10.5]$ increase caused by $2.5 \mathrm{mg} / \mathrm{kg}$ turmerone may result from an increased movement speed.

As shown in Tables 1, 2, 3, and 4, turmerone (2.5 mg/ $\mathrm{kg}$, p.o.) increased the level of 5-HT in cortex, striatum, hippocampus, and hypothalamus, the level of $\mathrm{NE}$ in striatum and hippocampus, the level of MHPG and DOPAC in hypothalamus, the level of 5-HIAA in striatum, and the level of DA in striatum, hippocampus, and hypothalamus. Turmerone $(5.0 \mathrm{mg} / \mathrm{kg}$, p.o.) increased the level of 5-HT in striatum, hippocampus and hypothalamus, the level of 5-HT in cortex, the level of 5-HIAA in striatum, the level of NE in cortex and hippocampus, and the level of DA in striatum, hippocampus, and hypothalamus. Furthermore, turmerone $(2.5,5.0 \mathrm{mg} /$ $\mathrm{kg}$, p.o.) decreased serotonin turnover ratio (5-HIAA/5HT) in cortex, striatum, hippocampus, and hypothalamus.

Table 5 summarizes the effect of turmerone on the activities of MAO-A in mouse brain. Turmerone (2.5, $5.0 \mathrm{mg} / \mathrm{kg}$ ) decreased the activity of MAO-A in the frontal cortex and hippocampus of mouse brain.

As shown in Figure 3, after the one-week treatment, turmerone $(2.5-5.0 \mathrm{mg} / \mathrm{kg})$ significantly decreased the levels of serum corticosterone in mice according to the swim stress test.

\section{Discussion}

Traditional Chinese Medicine is widely held to beneficial but generally neither the active principles nor their molecular targets are well defined [19], therefore, an understanding of the active component(s) and the mechanism(s) of action can make such medicines more acceptable.

The FST and TST are behavioral despair tests useful for probing the pathological mechanism of depression and for the evaluation of antidepressant drugs [30]. These tests are also a well-established system for screening new potent antidepressant drugs in mice [21]. Characteristic behavior scored in both tests is termed immobility, reflecting a behavioral state of despair (learned helplessness), as seen in human depression [24]. In order to investigate whether turmerone can produce chronic changes in depression-related behavior in FST and TST, we treated mice for one-week with different dosages via daily oral administration. Turmerone caused a reduction in the immobility time in FST and TST (Figure 1). The results presented here show, to our knowledge for the first time, that turmerone given orally is effective in producing significant antidepressant-like activity, when assessed in the FST and TST.

In FST and TST, anti-depressants can also be distinguished from stimulants, because stimulants cause marked motor stimulation, in contrast to antidepressants, which do not [31]. In order to determine whether turmerone actually possesses an antidepressant-like activity, we tested the locomotion counts to exclude the excitatory or inhibitory effects after administration of turmerone. Turmerone did not affect total movement and ambulatory movement at the same doses that significantly reduced immobility response in the FST and TST (Figure 2). The total distance increase caused by $2.5 \mathrm{mg} / \mathrm{kg}$ turmerone may result from an increased movement speed, so this should be further studied in the future. This hyperactivity

Table 5 Effect of one week of turmerone administration $(2.5,5.0 \mathrm{mg} / \mathrm{kg}$, p.o.) on MAO-A activity in different regions of the mouse brain

\begin{tabular}{lllcc}
\hline Groups & \multicolumn{3}{c}{ Activity of MAO-A $\left(\mathbf{U} \cdot \mathbf{h}^{-\mathbf{1}} \cdot \mathbf{m g}^{-\mathbf{1}}\right)$} \\
\cline { 2 - 5 } & Cortex & Striatum & Hippocampus & Hypothalamus \\
\hline Control & $11.4 \pm 1.1$ & $22.6 \pm 3.0$ & $29.6 \pm 1.0$ & $40.0 \pm 1.9$ \\
Turmerone $2.5 \mathrm{mg} / \mathrm{kg}$ & $8.1 \pm 0.8^{* *}$ & $22.2 \pm 0.6$ & $24.8 \pm 1.2$ & $36.6 \pm 1.7$ \\
Turmerone $5.0 \mathrm{mg} / \mathrm{kg}$ & $7.0 \pm 0.3^{* *}$ & $22.4 \pm 0.6$ & $22.7 \pm 0.9^{*}$ & $37.2 \pm 4.3$ \\
\hline
\end{tabular}

Values were the means \pm SEM $(n=10) .{ }^{*} p<0.05,{ }^{* *} p<0.01$ as compared with the control group. (One-way ANOVA followed by Scheffe's test). 


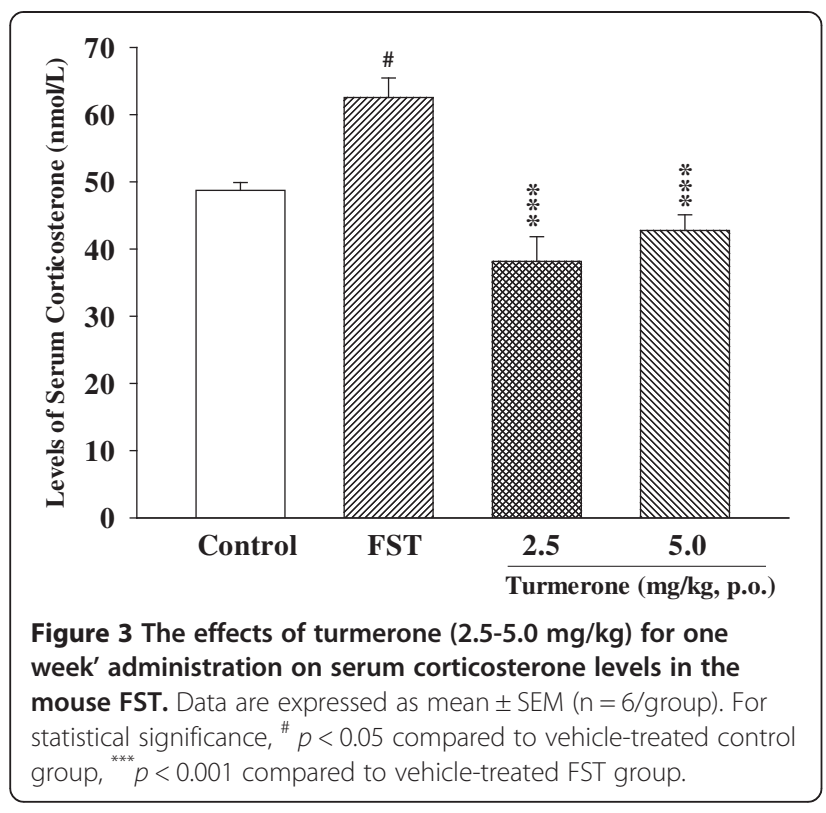

might explain the decreasing effect of turmerone on the immobility time in FST and TST.

Most currently clinically employed antidepressants exert their effects predominantly on one monoaminergic system, although it is unlikely that pharmacological manipulation of a single neurotransmitter in relative isolation would produce changes sufficient to remedy severe neurochemical dysfunction [32]. There is abundant evidence from anatomical, electrophysiological and pharmacological studies that the interactions between neurotransmitter systems are important [31]. Four brain regions were studied: the frontal cortex, the striatum, the hippocampus, and the hypothalamus, which are involved in important behavioral functions, such as emotion, motivation and learning and memory [33,34]. Abnormal monoamine levels in the four brain regions may be relevant to the depressed state. As shown in Tables 1, 2, 3, and 4, turmerone $(2.5 \mathrm{mg} / \mathrm{kg}$, p.o.) increased the level of $5-\mathrm{HT}$ in cortex, striatum, hippocampus, and hypothalamus, the level of NE in striatum and hippocampus, the level of MHPG and DOPAC in hypothalamus, the level of 5-HIAA in striatum, and the level of DA in striatum, hippocampus, and hypothalamus. Turmerone $(5.0 \mathrm{mg} / \mathrm{kg}$, p.o.) increased the level of 5-HT in striatum, hippocampus and hypothalamus, the level of 5-HT in cortex, the level of 5-HIAA in striatum, the level of NE in cortex and hippocampus, and the level of DA in striatum, hippocampus, and hypothalamus. These results indicated that the effect of turmerone on depression may be mediated via the increase in monoamines levels in the hippocampus, cortex, striatum, and hypothalamus of mice. Furthermore, turmerone $(2.5,5.0 \mathrm{mg} / \mathrm{kg}$, p.o.) decreased serotonin turnover ratio (5-HIAA/5-HT) in cortex, striatum, hippocampus, and hypothalamus. This result indicated that turmerone increased the level of serotonin in cortex, striatum, hippocampus, and hypothalamus. MAO is an important enzyme in the metabolism of a wide range of monoamine neurotransmitters, including NE, DA, and $5-\mathrm{HT}$.

MAO-A inhibitors are efficacious for treating depression while the inhibitors of MAO-B appear to be effective in preventing and treating Parkinson's disease. Furthermore, a positive correlation between oxidative stress and depression [35] is reported in some studies. Turmerone (2.5, $5.0 \mathrm{mg} / \mathrm{kg}$ ) decreased the activity of MAO-A in the frontal cortex and hippocampus of mouse brain. The HPA axis plays a key role in the physiological response to various stressful situations [36]. Continuous activation of the HPA axis, especially abnormally increased serum corticosterone levels, leads to hormonal imbalance and even to more severe diseases such as depressive disorder both in rodents and humans $[37,38]$. The FST is known to be a potent activator of the HPA axis [39]. After the oneweek treatment, turmerone $(2.5-5.0 \mathrm{mg} / \mathrm{kg})$ significantly decreased the levels of serum corticosterone in mice according to the swim stress test (Figure 3). The result strongly suggested that turmerone exerted antidepressant activity, at least in part, by regulating serum corticosterone levels, thus normalizing the HPA axis hyperactivity.

\section{Conclusion}

In conclusion, turmerone reduced immobility time in the mouse FST and TST. The results suggest that the antidepressant-like effect of turmerone in FST is mediated, at least in part, by the inhibition of MAO-A, and reversed the swim stress -induced increases in serum corticosterone levels. Our study suggest that turmerone possess potent antidepressant properties.

\section{Competing interests}

The authors declare no competing interests.

\section{Authors' contributions}

LYW and WHP designed the work. JCL, CYL, JCT and HCH analyzed and interpreted data for the work. All authors participated in critical manuscript revision and approved the final manuscript.

\section{Acknowledgments}

This study is supported in part by the National Science Council, Taiwan (NSC 101-2320-B-039-032-MY2), Taiwan Department of Health Clinical Trial and Research Center of Excellence (DOH100-TD-B-111-004) and Committee on Chinese Medicine and Pharmacy, Department of Health, Executive Yuan (CCMP102-RD-104, CCMP102-RD-019).

\section{Author details}

${ }^{1}$ School of Pharmacy, College of Pharmacy, China Medical University, Taichung 404, Taiwan. ${ }^{2}$ Department of Health and Nutrition Biotechnology, College of Health Science, Asia University, Taichung 404, Taiwan.

${ }^{3}$ Department of Chinese Pharmaceutical Sciences and Chinese Medicine Resources, College of Pharmacy, China Medical University, No. 91, Hsueh-Shih Road, Taichung 404, Taiwan. ${ }^{4}$ Department of Nursing, Jen-Teh Junior College of Medicine, Nursing and Management, No. 79-9, Sha-Luen-Hu, Xi Zhou Li, Hou-Loung Town, Miaoli County 35664, Taiwan. ${ }^{5}$ School of Chinese Medicine 
for Post Baccalaureate, I-Shou university, No.1, Sec. 1, Syuecheng Rd., Dashu District, Kaohsiung City 84001, Taiwan.

Received: 7 August 2013 Accepted: 29 October 2013 Published: 1 November 2013

\section{References}

1. Dang H, Chen Y, Liu X, Wang Q, Wang L, Jia W, Wang Y: Antidepressant effects of ginseng total saponins in the forced swimming test and chronic mild stress models of depression. Prog Neuropsychopharmacol Biol Psychiatry 2009, 33:1417-1424.

2. Yi LT, Xu HL, Feng J, Zhan X, Zhou LP, Cui CC: Involvement of monoaminergic systems in the antidepressant-like effect of nobiletin. Physiol Behav 2011, 102:1-6.

3. Delgado PL: Depression: the case for a monoamine deficiency. J Clin Psychiatry 2000, 61:7-11.

4. Chuang CY, Shi YC, You HP, Lo YH, Pan TM: Antidepressant effect of GABA-rich monascus-fermented product on forced swimming rat model. J Agric Food Chem 2011, 59:3027-3034.

5. Fava M: Diagnosis and definition of treatment-resistant depression. Biol Psychiatry 2003, 53:649-659.

6. Freitas AE, Budni J, Lobato KR, Binfaré RW, Machado DG, Jacinto J, Veronezi PO, Pizzolatti MG, Rodrigues AL: Antidepressant-like action of the ethanolic extract from Tabebuia avellanedae in mice: evidencefor the involvement of the monoaminergic system. Prog Neuropsychopharmacol Biol Psychiatry 2010 34:335-343.

7. Bertoli A, Giovannini A, Ruffoni B, Guardo AD, Spinelli G, Mazzetti M, Pistelli L: Bioactive constituent production in St. John's Wort in vitro hairy roots. Regenerated plant lines. J Agric Food Chem 2008, 56:5078-5082.

8. Yu ZF, Kong LD, Chen Y: Antidepressant activity of aqueous extracts of Curcuma longa in mice. J Ethnopharmacol 2002, 83:161-165.

9. Kumar A, Chomwal R, Kumar P, Sawal R: Anti-inflammatory and wound healing activity of Curcuma aromatica salisb extract and its formulation. J Chem Pharm Res 2009, 1:304-310.

10. Al-Reza SM, Rahman A, Sattar MA, Rahman MO, Fida HM: Essential oil composition and antioxidant activities of Curcuma aromatica Salisb. Food Chem Toxicol 2010, 48:1757-1760.

11. Choochote W, Chaiyasit D, Kanjanapothi D, Rattanachanpichai E, Jitpakdi A, Tuetun B, Pitasawat B: Chemical composition and anti-mosquito potential of rhizome extract and volatile oil derived from Curcuma aromatica against Aedes aegypti (Diptera: Culicidae). J Vector Ecol 2005, 30:302-309.

12. $W u W Y, X u Q$, Shi LC, Zhang WB: Inhibitory effects of Curcuma aromatica oil on proliferation of hepatoma in mice. World J Gastroenterol 2000, 6:216-219.

13. Lee $Y L$, Weng CC, Mau JL: Antioxidant properties of ethanolic and hot water extracts from the rhizome of curcuma aromatic. J Food Biochem 2007, 31:757-771.

14. Micó JA, Ardid D, Berrocoso E, Eschalier A: Antidepressants and pain. Trends Pharmacol Sci 2006, 27:348-354.

15. Krell HV, Leuchter AF, Cook IA, Abrams M: Evaluation of reboxetine, a noradrenergic antidepressant, for the treatment of fibromyalgia and chronic low back pain. Psychosomatics 2005, 46:379-384.

16. Kulkarni SK, Bhutani MK, Bishnoi M: Antidepressant activity of curcumin: involvement of serotonin and dopamine system. Psychopharmacology (Berl) 2008, 201:435-442.

17. Bhutani MK, Bishnoi M, Kulkarni SK: Anti-depressant like effect of curcumin and its combination with piperine in unpredictable chronic stress-induced behavioral, biochemical and neurochemical changes. Pharmacol Biochem Behav 2009, 92:39-43.

18. Xu Y, Ku BS, Yao HY, Lin YH, Ma X, Zhang YH, Li XJ: Antidepressant effects of curcumin in the forced swimming test and olfactory bulbectomy models of depression in rats. Pharmacol Biochem Behav 2005, 82:200-206.

19. Sandur SK, Pandey MK, Sung B, Ahn KS, Murakami A, Sethi G, Limtrakul P, Badmaev V, Aggarwal BB: Curcumin, demethoxycurcumin, bisdemethoxycurcumin, tetrahydrocurcumin and turmerones differentially regulate anti-inflammatory and anti-proliferative responses through a ROS-independent mechanism. Carcinogenesis 2007, 28:1765-1773.

20. Cryan JF, Markou A, Lucki I: Assessing antidepressant activity in rodents: recent developments and future needs. Trends Pharmacol Sci 2002, 23:238-245
21. Porsolt RD, Bertin A, Jalfre M: Behavioral despair in mice: a primary screening test for antidepressants. Arch Int Pharmacodyn Ther 1977, 229:327-336.

22. Zomkowski AD, Santos AR, Rodrigues AL: Involvement of opioid system in the agmatine antidepressant-like effect in the forced swimming test. Neurosci Lett 2005, 381:279-283.

23. Zhou D, Jin H, Lin HB, Yang XM, Cheng YF, Deng FJ, Xu JP: Antidepressant effect of the extracts from Fructus Akebiae. Pharmacol Biochem Behav 2010, 94:488-495.

24. Steru L, Chermat R, Thierry B, Simon P: The tail suspension test: a new method for screening antidepressants in mice. Psychopharmacology (Berl) 1985, 85:367-370.

25. Rodrigues AL, Rocha JB, Mello CF, Souza DO: Effect of perinatal lead exposure on rat behaviour in open-field and two-way avoidance tasks. Pharmacol Toxicol 1996, 79:150-156.

26. Renard CE, Dailly E, David DJ, Hascot M, Bourin M: Monoamine metabolism changes following the mouse forced swimming test but not the tail suspension test. Fundam Clin Pharmacol 2003, 17:449-455.

27. Schurr A, Livne A: Different inhibition of mitochondrial monoamine oxidase from brain by hashish components. Biochem Pharmacol 1976, 25:1201-1203.

28. Lowry OH, Rosebrough NJ, Far AL, Randall R: Protein measurement with folin phenol reagent. J Biol Chem 1951, 193:265-275.

29. Buchenauer T, Behrendt P, Bode FJ, Horn R, Brabant G, Stephan M, Nave H: Diet-induced obesity alters behavior as well as serum levels of corticosterone in F344 rats. Physiol Behav 2009, 98:563-569.

30. Porsolt RD, Bertin A, Jalfre M: Behavioural despair in rats and mice: strain differences and the effects of imipramine. Eur J Pharmacol 1978, 51:291-294

31. Borsini F, Meli A: Is the forced swimming test a suitable model for revealing antidepressant activity? Psychopharmacology (Berl) 1998, 94:147-160.

32. Li S, Wang C, Li W, Koike K, Nikaido T, Wang MW: Antidepressant-like effects of piperine and its derivative, antiepilepsirine. J Asian Nat Prod Res 2007, 9:421-430.

33. Xu Y, Wang Z, You W, Zhang X, Li S, Barish PA, Vernon MM, Du X, Li G, Pan J, Ogle WO: Antidepressant-like effect of trans-resveratrol: Involvement of serotonin and noradrenaline system. Eur Neuropsychopharmacol 2010, 20:405-413.

34. Shiflett MW, Balleine BW: Contributions of ERK signaling in the striatum to instrumental learning and performance. Behav Brain Res 2011, 218:240-247.

35. Herken H, Gurel A, Selek S, Armutcu F, Ozen ME, Bulut M, Kap O, Yumru M, Savas HA, Akyol O: Adenosine deaminase, nitric oxide, superoxide dismutase, and xanthine oxidase in patients with major depression: impact of antidepressant treatment. Arch Med Res 2007, 38:247-252.

36. Szafarczyk A, Ixart G, Gaillet S, Siaud P, Barbanel G, Malaval F, Assenmacher I: Stress. Neurophysiologic studies. Encéphale 1993, 1:137-142.

37. Asnis GM, Halbreich U, Ryan ND, Rabinowicz H, Puig-Antich J, Nelson B, Friedman $\mathrm{JH}$ : The relationship of the dexamethasone suppression test (1 $\mathrm{mg}$ and $2 \mathrm{mg}$ ) to basal plasma cortisollevels in endogenous depression. Psychoneuroendocrinology 1987, 12:295-301.

38. Ayensu WK, Pucilowski O, Mason GA, Overstreet DH, Rezvani AH, Janowsky DS: Effects of chronic mild stress on serum complement activity, saccharin preference, and corticosterone levels in flinders lines of rats. Physiol Behav 1995, 57:165-169.

39. Drossopoulou G, Antoniou K, Kitraki E, Papathanasiou G, Papalexi E, Dalla C, Papadopoulou-Daifoti Z: Sex differences in behavioral, neurochemical and neuroendocrine effects induced by the forced swim test in rats. Neuroscience 2004, 126:849-857.

doi:10.1186/1472-6882-13-299

Cite this article as: Liao et al.: Antidepressant-like activity of turmerone in behavioral despair tests in mice. BMC Complementary and Alternative Medicine 2013 13:299. 